\title{
Non-structural Performance of Pastes and Mortars Fabricated from Alkali Activated Electric Arc Furnace Slag
} \author{
and Nuno Cristelo ${ }^{1}$ \\ ${ }^{1}$ Department of Engineering, University of Trás-os-Montes e Alto Douro, Portugal \\ ${ }^{2}$ Department of Chemistry, University of Trás-os-Montes e Alto Douro, Portugal \\ ${ }^{3}$ Department of Mechanical Engineering, University of Minho, Portugal \\ ${ }^{4}$ Department of Civil Engineering, University of Porto, Portugal \\ ${ }^{5}$ Department of Civil Engineering, University of Minho, Campus de Azurém, Portugal \\ ${ }^{6}$ Department of Geology, University of Trás-os-Montes e Alto Douro, Portugal
}

Filipe Almeida ${ }^{1 *}$, Pedro Tavares ${ }^{2}$, Fernando Castro ${ }^{3}$, Maria de Lurdes Lopes ${ }^{4}$, Tiago Miranda ${ }^{5}$, Luis Sousa ${ }^{6}$

*Corresponding author: Filipe Almeida, CQVR, Department of Engineering, University

Received Date: May 31, 2019

of Trás-os-Montes e Alto Douro, 5000-801 Vila Real, Portugal.

Published Date: June 13, 2019

\begin{abstract}
With the implementation of legislation on waste management in the European Union, which sets objectives in terms of promoting the re-use and recycling of products, the industry and the academic community have been making additional efforts in order to develop solutions that aim to use industrial by-products as raw materials, more specifically, in the study of alternative binders to Portland cement. In this work, an extensive experimental campaign is carried out to characterise, from the non-structural point of view, a set of alkali activated mixtures fabricated with electric arc furnace slag (EAFS) and phosphate sludge (PS) as the precursor, and two different activators (a commercial solution composed by sodium hydroxide and sodium silicate, and a solution used to clean the sand moulds from the aluminium processing industry). Results reveal that the mixtures based on EAFS present some handicaps in terms of shrinkage and workability, and that these properties are influenced by the nature of the activator and the presence of the PS.
\end{abstract}

Keywords: Electric arc furnace slag; Phosphate sludge; Alkali activated mortars; Non-structural behaviour

List of Abbreviations:

CS - solution used to clean the sand moulds from the Portuguese aluminium processing industry; EAFS - electric arc furnace slag; FS - flexural strength tests; HS - solution containing commercial sodium hydroxide and sodium silicate; LVDT - linear variable differential transformer; PS phosphate sludge; PSD - particle size distribution; UCS - uniaxial compressive strength tests

List of Notations

$\begin{array}{ll}C_{m} & \text { is the coefficient of water absorption for mortars other than renovation mortars } \\ C_{r} & \text { is the coefficient of water absorption for renovation mortars } \\ \mathrm{f} & \text { is the factor of molarity } \\ \mathrm{m} & \text { is the mass of the sample } \\ \mathrm{M}_{0} & \text { is the dry mass of the specimen } \\ M_{1} & \text { is the mass of the specimen after soaking for } 10 \text { minutes } \\ M_{2} & \text { is the mass of the specimen after soaking for } 90 \text { minutes } \\ M_{3} & \text { is the mass of the specimen after soaking for } 24 \text { hours } \\ m_{d} & \text { is the dry weight of the specimen } \\ m_{h} & \text { is the immersed weight of the specimen } \\ m_{s} & \text { is the saturated weight of the specimen } \\ p_{0} & \text { is the open porosity of the specimen }\end{array}$




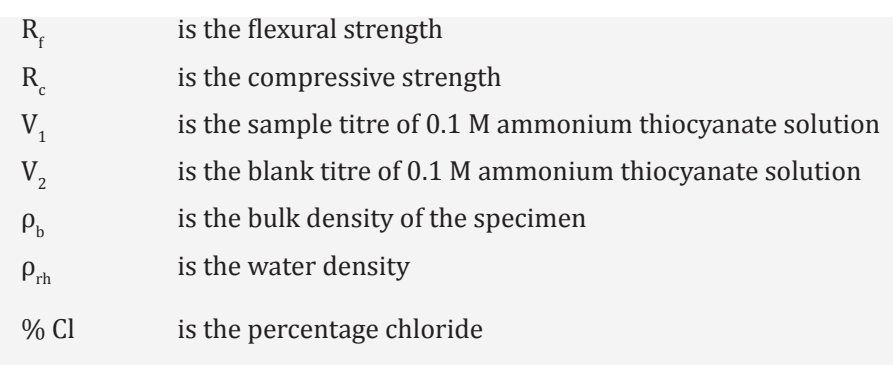

\section{Introduction}

Today, more than ever, the protection of the environment is a priority issue and the industry are being compelled to adopt proper and responsible behaviours, which includes the exploration, until the exhaustion of all possibilities, of using industrial by-products that show some potential as raw materials for specific applications. Within the framework of the global vector known as waste valorisation, the construction industry may play a key role regarding the aforementioned outcome, by promoting the development of more environmentally friendly products. Furthermore, the time scale until these solutions are implemented in the market depends, largely, on the reliability of the results presented by the academic community. Electric arc furnace slag (EAFS), which is an industrial by-product of the steel-making process, has been the subject of extensive research aiming the application of this material in the construction industry, usually in the role of the aggregate [1-4]. Concerning its use as an aggregate (i.e. in substitution of natural, more traditional aggregates, for the production of concrete), several studies demonstrated that the mechanical performance of such concretes is suitable, when compared with ordinary concretes [5-7]. However, in order to limit the increase in density, partial replacements only should be considered [8]. Fewer studies have focused on the use of EAFS as a part of the binder, mostly based on its essentially crystalline nature and on its relatively high iron content [9]. In short, although the EAFS is preferentially used as an aggregate, some interesting results were attained, in terms of mechanical performance, when the EAFS, in powder form, was used in cementitious blends, usually incorporating Portland cement [1012].

The procedure known as alkaline activation is being developed, in the last two decades, to produce binders from either industrial by-products or natural materials (e.g. kaolin). There are numerous materials that have been used in a precursor role, like fly ash (usually with a low calcium content) or blast furnace slag (with a high content of calcium, such as the EAFS) [13-16]. The earlier development of appreciable mechanical strengths is one of the most meaningful features of the alkaline cements based on blast furnace slag and other high-calcium precursors. However, these highcalcium AA binders face some important setbacks, such as shrinkage or rapid hardening [17]. As a valuable source of aluminium, silicon and calcium, EAFS is an industrial by-product that, apparently, meets several of the required conditions to be used as a precursor in alkali activated blends, and current research is now targeting its functional optimization. Even though the volume of researchbased knowledge regarding alkali activated materials is constantly growing [18,19], information on its non-structural behaviour is clearly less than that available concerning its structural behaviour, which acts as a hindrance when potential industrial partners need confidence and security to move forward. By analyzing a set of nonstructural properties, this work aims to be a contribution to a more consolidated knowledge about this kind of alkali activated pastes and mortars and, therefore, to assist the decision-making regarding the applications that can be developed. The research presented was preceded by a preliminary campaign, which tested the mechanical performance (through uniaxial compressive strength tests) of a wide spectrum of alkali activated pastes, composed by electric arc furnace slag (EAFS) and phosphate sludge (PS). Based on the results of this preliminary phase, which are not presented, the two most performing combinations were selected and used in the fabrication of mortars. Silica sand was used, in weight percentages of $10 \%$, $20 \%$ and $30 \%$, by weight of the paste, and the resulting mortars were submitted to flexural and compressive strength tests. Four mixtures (two pastes and two mortars) were then submitted to an extensive experimental campaign that included the assessment of the following properties: bulk density, porosity, shrinkage, water absorption, water-soluble chloride content and several fluidity related tests. Considering the lack of standards for alkali activated materials, tests were carried out based on the recommendations of the existing standards for cement and mortars.

\section{Materials and Methods}

\section{Materials}

The two residues used as precursors, EAFS and PS, are generated in the metallurgical and metal-mechanic industry, respectively, and were provided by Portuguese companies. They were both presented as a white power, and their particle size distribution (PSD) curves reveal a maximum particle size of $250 \mu \mathrm{m}$. The PSD curve of the river sand, used to fabricate the mortars, was rectified to comply with the maximum grain size defined by EN 196-1:2016 [20]. The PSD curves of the residues are shown in Figure 1(Figure 1).

The chemical composition of the precursors is shown in Table 1. The EAFS revealed a significant calcium content (49\%) and a low aluminium content (7.4\%), while the PS is mostly constituted by phosphorus (44\%) and iron (35\%). Even if the chemical composition of the EAFS revealed some potential for the precursor 
role in alkali activation reactions, it was decided to incorporate a secondary additional residue, namely the PS, which is not an aluminosilicate, in order to assess the possible recycling of the high phosphorous content of the PS in alkaline activation-based materials [21-23] (Table 1).
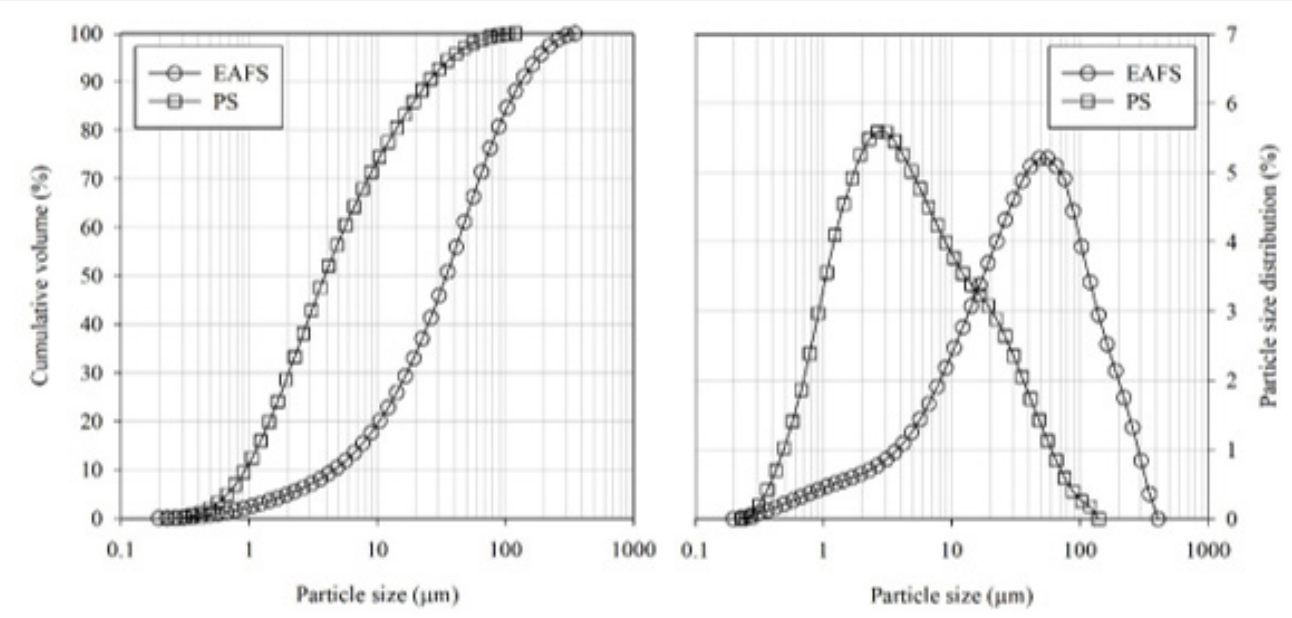

Figure 1: Cumulative particle size and particle size distribution of the EAFS and PS.

Table 1: Chemical composition (wt. \%) of the EAFS and PS obtained through XRF analysis.

\begin{tabular}{|c|c|c|}
\hline Element & EAFS & PS \\
\hline $\mathrm{Na}_{2} \mathrm{O}$ & 0.13 & 3.6 \\
\hline $\mathrm{SiO}_{2}$ & 18.8 & - \\
\hline $\mathrm{Al}_{2} \mathrm{O}_{3}$ & 7.4 & - \\
\hline $\mathrm{MgO}$ & 5.4 & - \\
\hline $\mathrm{K}_{2} \mathrm{O}$ & 0.03 & - \\
\hline $\mathrm{CaO}$ & 49.5 & 1 \\
\hline $\mathrm{TiO}_{2}$ & 0.4 & - \\
\hline $\mathrm{Fe}_{2} \mathrm{O}_{3}$ & 10.1 & 35.2 \\
\hline $\mathrm{ZnO}^{\mathrm{MnO}}$ & 1.25 & 12.9 \\
\hline $\mathrm{BaO}$ & 1.43 & - \\
\hline $\mathrm{SO}_{3}$ & 0.1 & - \\
\hline $\mathrm{P}_{2} \mathrm{O}_{5}$ & 3.42 & - \\
\hline $\mathrm{Others}$ & 0.07 & 43.7 \\
\hline
\end{tabular}

Based on UNE 80103:2013 [24], specific gravity values of $3.11 \mathrm{~g} / \mathrm{cm} 3$ and $2.66 \mathrm{~g} / \mathrm{cm} 3$ were obtained for the EAFS and PS, respectively, using a Le Chatelier volumenometer. Mineralogy was analyzed with a BRUKER D8 ADVANCE diffractometer, with CuK radiation, $40 \mathrm{kV}$ and $30 \mathrm{~mA}$, fitted with a LYNXEYE super speed detector. The resulting diffractograms of the original materials are presented in Figure 2. The scans covered a $2 \theta$ range of 5 to $60^{\circ}$, with a nominal step size of $0.01973^{\circ}$ and $0.5 \mathrm{~s} / \mathrm{step}$. The X-Ray diffractogram of the EAFS showed calcium silicate, gehlenite, and calcium-magnesium-iron as the main phases, with some traces of magnetite and larnite. The halo between the 30 and $40(\underline{0} 2 \theta)$ angles reveals the presence of some vitreous mass. Mineralogically, the PS identified is essentially strength. The presence of amorphous material in the PS was also detected, in several 'bumps' throughout the baseline (Figure 2).

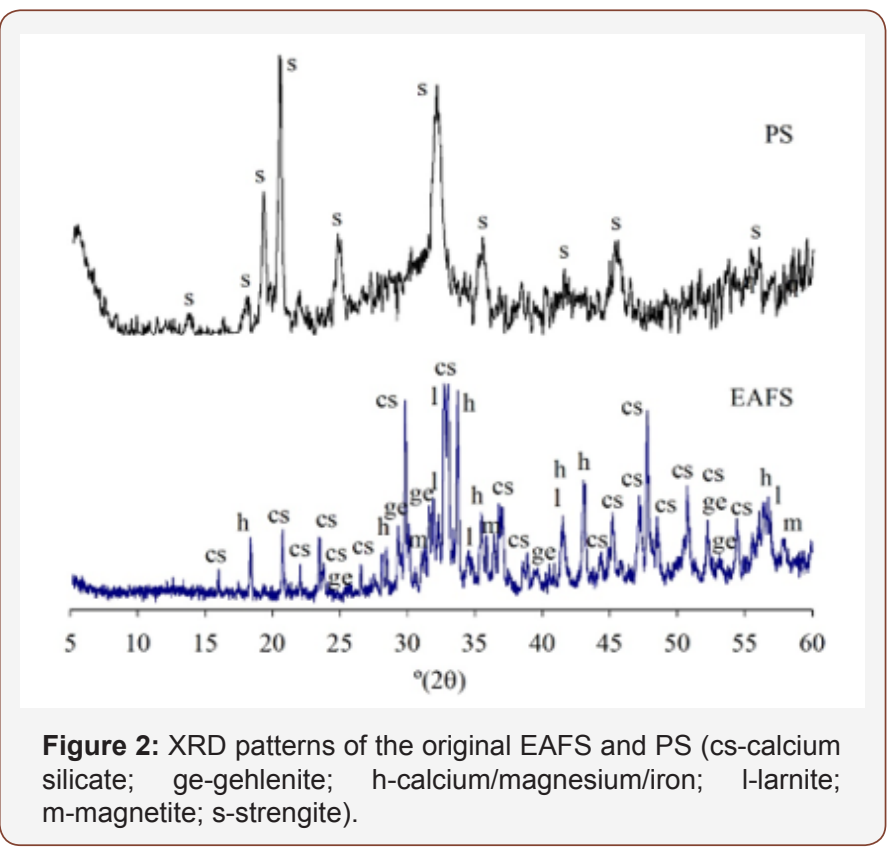

Two different activators were used: a solution containing commercial sodium hydroxide and sodium silicate (HS), with a hydroxide / silicate ratio of 2; and a solution used to clean the sand moulds from the Portuguese aluminium processing industry (CS). The sodium hydroxide, supplied in pellets with a specific gravity of 2.13 at $20^{\circ} \mathrm{C}$ ( $99 \mathrm{wt} . \%$ ), was dissolved in deionized water to achieve a concentration of $5 \mathrm{M}$. The silicate presented a unit weight of 1.464 $\mathrm{g} / \mathrm{cm} 3\left(\right.$ at $20^{\circ} \mathrm{C}$ ), a SiO2/ $\mathrm{Na}_{2} \mathrm{O}$ weight ratio of 2.0 (molar oxide ratio of 2.063 ) and $\mathrm{a} \mathrm{Na}_{2} \mathrm{O}$ concentration in the solution of $13.0 \%$. The CS was used as received in the laboratory, after homogenization, and a concentration of approximately $7 \mathrm{M}$ was determined.

\section{Testing procedures and specimen production}

Fabrication of the specimens comprised an initial mixing stage, performed on a counter mixer, followed by a 30 -second vibration 
phase, on a vibrating table. The pastes were then casted into prismatic moulds ( $4 \times 4 \times 16 \mathrm{~cm})$, which were left to cure for 20 hours, at $80^{\circ} \mathrm{C}$. Tests were conducted 24 hours after the start of the mixing stage. The composition of the pastes is shown in Table 2. Due to the nature of the residues and activators, it was not possible to set the same activator / solids ratio for all mixtures. These ratios were adjusted considering the workability exhibited by the mixtures. Two main groups were defined, based on the activator (HS or CS). For each group, one paste and three mortars were studied, each with a different aggregate (sand) content of $10 \%, 20 \%$ and $30 \%$, by dry weight. Also included is the activator / solids ratio for each mixture (the solids were defined as the sum of the precursors and the aggregate) (Table 2).

Table 2: Composition of the mixtures (Ac: activator; Sol: precursor + aggregate).

\begin{tabular}{|c|c|c|c|c|}
\hline Label & EAFS (wt.\%) & PS (wt.\%) & SA (wt.\%) & Ac / Sol \\
\hline BHS & 100 & - & - & 0.39 \\
\hline MHS1 & 90 & - & 10 & 0.35 \\
\hline MHS2 & 80 & - & 20 & 0.35 \\
\hline MHS3 & 70 & - & 30 & 0.39 \\
\hline BCS & 50 & 50 & - & 0.5 \\
\hline MCS1 & 45 & 45 & 10 & 0.39 \\
\hline MCS2 & 40 & 40 & 20 & 0.38 \\
\hline MCS3 & 35 & 35 & 30 & 0.32 \\
\hline
\end{tabular}

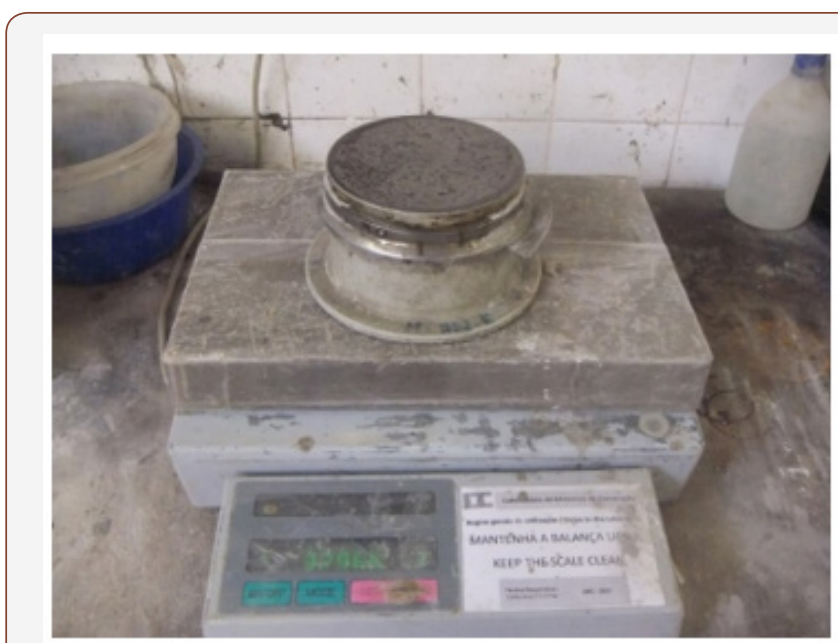

Figure 3: Determination of the bulk density of fresh mixtures, after vibration of the paste inside the bowl.

Uniaxial compressive (UCS) and flexural (FS) strength tests were conducted based on the recommendations of EN 196-1:2016 [20]. Compressive strength tests were carried out on the two halves resulting from the prismatic specimen which was initially submitted to a flexural test. A servo-hydraulic testing machine, fitted with either a $10 \mathrm{kN}$ or a $50 \mathrm{kN}$ load cell, depending on the flexural or compressive test being performed, respectively. The tests were carried out under monotonic displacement control, at rates of 0.4 $\mathrm{mm} / \mathrm{min}$ (UCS) and $0.2 \mathrm{~mm} / \mathrm{min}$ (FS). The relative displacement between the loading plates in the compressive tests was acquired by a linear variable differential transformer (LVDT), enabling the registration of the full stress-strain curve for each test. Prior to testing, all specimens were weighted and measured. The strength values presented in this work represent the arithmetic average of three (flexural tests) and six (compressive tests) specimens. The determination of the bulk density of fresh mixtures was carried out in accordance with EN 1015-6:1998 [25]. A 1-liter capacity metallic bowl was filled, in excess, with the paste, and vibrated (on a vibrating table), until no further setting was detected. The remaining excess paste was removed with a pallet knife, after which both the mass and the volume were registered (Figure 3). The bulk density of the hardened mixtures was assessed during the porosity test, as described further ahead (Figure 3).

Considering the lack of a specific standard to evaluate the porosity of this type of mixtures, the tests were carried out based on the procedures displayed in NP EN 1936:2008 [26]. For each mixture, three cubic specimens $(4 \mathrm{~cm}$ ) were prepared and dried, in an oven, at $70^{\circ} \mathrm{C}$, until constant mass was reached. Test procedures included three main steps, carried out in three consecutive days: i) installation of the specimens in a desiccator (Figure 4a), connected to a vacuum pump, which produced a -26 bar pressure for 24 hours; ii) the container, still under vacuum, was filled with water until the specimens were submerged; iii) after 24 hours, the vacuum was eliminated, and the specimens remained submerged for further 24 hours. Throughout the test, the dry, saturated and submerged (hydrostatic weighing, Figure $4 \mathrm{~b}$ ) weights were registered. The porosity, as well as the bulk density, was then estimated based on the equations presented in NP EN 1936:2008 [26] (Figure 4).

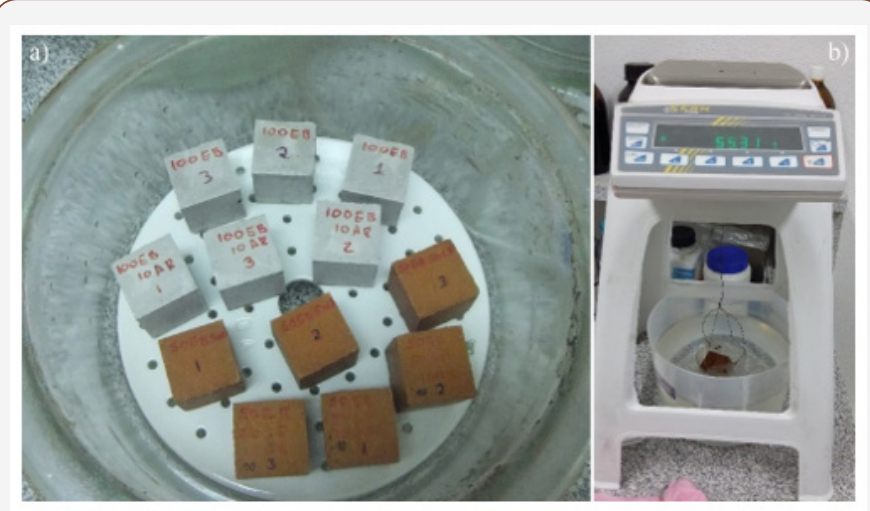

Figure 4: Determination of porosity, showing the specimens inside the vacuum desiccator (a) and the hydrostatic weighing (b).

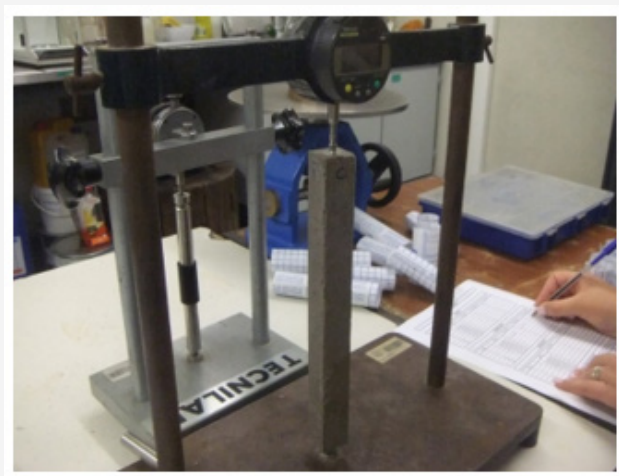

Figure 5: Shrinkage test: a) verifying the readings of the length comparator with the calibration rod; b) specimen measurements. 
Drying shrinkage tests were carried out based on the procedures established in BS EN 12617-4:2002 [27]. For each mixture, three prismatic specimens, with $25 \times 2.5 \times 2.5 \mathrm{~cm}$ were prepared. The specimens were left inside the mould for 24 hours, after which they were stored at $20^{\circ} \mathrm{C}$ and $65 \%$ (relative humidity). Shrinkage was then measured after $1,3,7,14,28$ and 56 days, after demoulding. A digital length comparator was used to carry out the measurements (Figure 5). The results presented are the average of four readings per specimen (Figure 5).

The water absorption coefficient of the hardened mixtures, due to capillary, was assessed using the procedure described in EN 1015-18:2002 [28]. Three prismatic specimens, with dimensions $16 \times 4 \times 4 \mathrm{~cm}$, were prepared for each mixture, and submitted to a total curing period of 28 days. In the first two days the specimens remained in the moulds, under a temperature of $20^{\circ} \mathrm{C}$. After demoulded, the curing conditions were maintained for further 5 days. For the remaining 21 days, specimens were submitted to a relative humidity of $65 \%$, while still at $20^{\circ} \mathrm{C}$. After this 28 -day curing period the specimens were sealed, with aluminium tape, broken in two halves, and placed in an oven at $60^{\circ} \mathrm{C}$, until constant mass was reached. The next step was to install the specimens in perforated steel supports, with the broken surface facing down, which were then placed inside trays with a $10 \mathrm{~mm}$ thick water layer (Figure 6). After 10 and 90 minutes, the specimens were removed from the trays and weighed, and restored back to the tray. The weighting was then repeated after 24 hours, and the specimens were, once again, broken in two halves, in order to measure the height of water penetration(Figure 6).

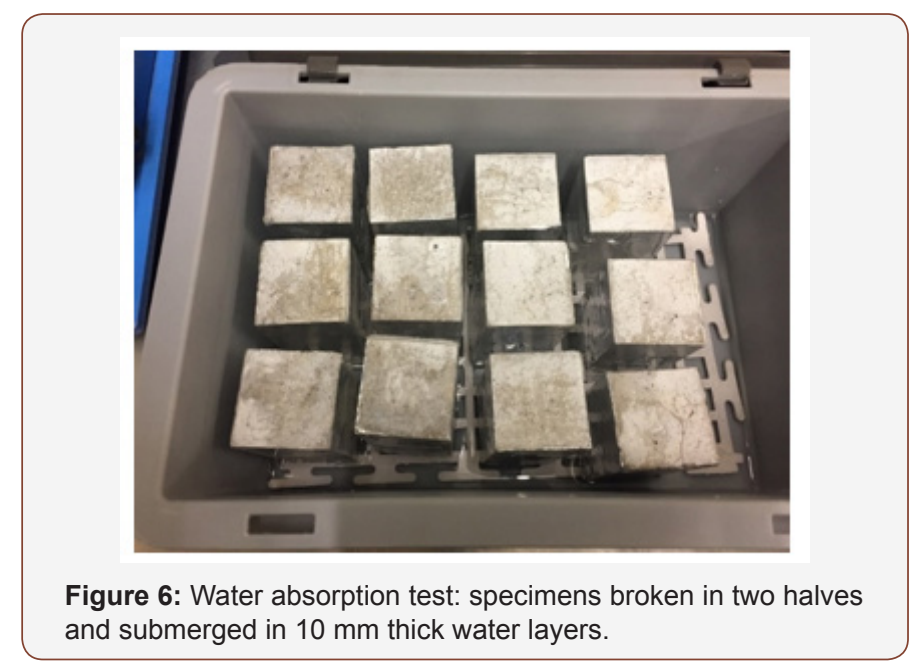

The water-soluble chloride content of mixtures was evaluated considering the procedure displayed in EN 1015-17:2000 [29]. One prismatic specimen $(16 \times 4 \times 4 \mathrm{~cm})$ was prepared for each mixture, and submitted to a curing period of 20 hours, at $80^{\circ} \mathrm{C}$. After demoulding, specimens were stored in an oven, at $100^{\circ} \mathrm{C}$, until constant mass was attained. After drying, the specimens were crushed in order to obtain $50 \mathrm{~g}$ of particles below $125 \mu \mathrm{m}$, from which $10 \mathrm{~g}$ were collected and thoroughly mixed with $100 \mathrm{ml}$ of distilled water. The mixture was then left for 20 hours, before filtration and subsequent titration, using ammonium thiocyanate as the titrant. Several tests were also performed to analyze the workability and fluidity of the pastes and mortars. The standard consistence and setting time were evaluated in accordance with EN 196-3:2016 [30], using a Vicat apparatus. The consistency test consists of releasing a plunger into a mixture sample casted in a Vicat mould. Different mixtures, with different water contents, should then be tested, until a distance of $6 \pm 2 \mathrm{~mm}$ between the plunger and the baseplate is obtained, so that the corresponding consistency can be defined as 'normal'. However, the role of this test in the framework of the present study was the comparison of the relative performance between the four selected mixtures and, thus, no additional water contents were tested. The initial setting time is measured between the 'zero' instance (when the needle punctures the full height of the specimen) and the instance when a distance of $6 \pm 3 \mathrm{~mm}$ is registered between the tip of the needle and the baseplate. The final setting time is then established when the needle, now with a $5 \mathrm{~mm}$ diameter ring attached, penetrates only $0.5 \mathrm{~mm}$ into the sample.

The fluidity and/or the wetness of the fresh mixtures were assessed using the flow cone and the flow table tests, based on the recommendations of NP EN 445:2008 [31] and EN 1015-3:1999 [32], respectively. The flow cone test consists on measuring the time that 1 litre of mixture requires to flow through a standard cone (Figure 7a). However, it was not possible to perform this test with any of the mixtures since none flowed through the cone in useful time. Nevertheless, it should be noted that the mixture showing the largest quantity of material flowing through the cone was the BCS, while no passing volume was observed for either of the HSbased mixtures. The flow table test, for assessing the consistency of the fresh state materials (Figure 7b), is started by introducing a sample in a truncated conical mould, in two compacted layers. After careful cleaning the visible disk surface, the mould is slowly lifted and the sample is spread by jolting the flow table 15 times $(1 / \mathrm{s})$. Finally, the diameter of the spread sample is measured, in two directions(Figure 7).

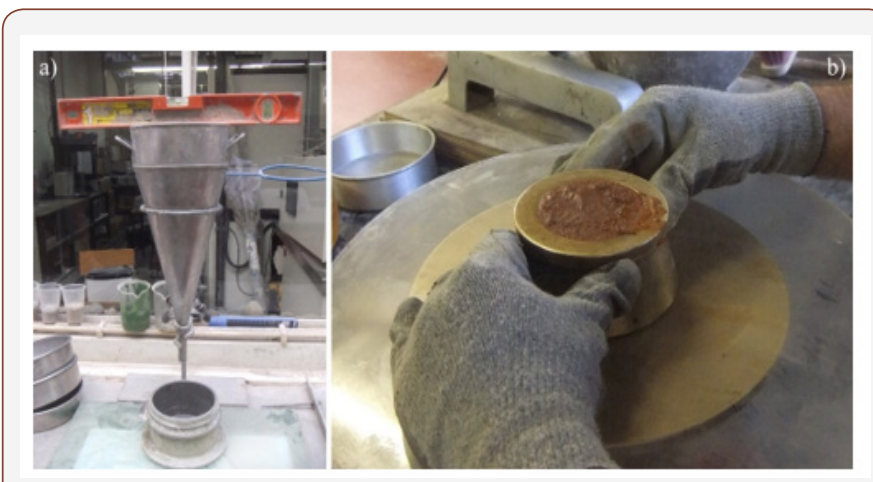

Figure 7: Fluidity analyses: a) set up of flow cone test; b) flow table test.

\section{Result and Discussion}

\section{Flexural and compressive strength tests}

Figure 8 displays the flexural and compressive strength results. The most remarkable aspect resulting from these tests is that, as expected, the mechanical performance of the mixtures improved 
with the addition of the aggregate, with an optimum content between $10 \%$ and $20 \%$. In terms of flexural strength (Rf), an aggregate content of $20 \%$ was the most effective for the HS binder (MHS2, Rf = $1.27 \mathrm{MPa}$ ), while a 30\% aggregate content produced the best performance among the CS binder mixtures (MCS3, Rf = $1.53 \mathrm{MPa}$ ). In terms of compressive strength (Rc), a lower optimum aggregate content $(10 \%)$ was obtained, for both types of activator. For the HS activator, the compressive strength of the MHS1 (10\%, $\mathrm{Rc}=6.58 \mathrm{MPa})$ and MHS2 $(20 \%, \mathrm{Rc}=6.80 \mathrm{MPa})$ mortars was very similar. These values represent a strength increase of $52 \%$, relatively to the strength obtained by the BHS paste. Considering the mixtures manufactured with the CS activator, the optimum aggregate content was $10 \%$ (MCS1), with a compressive strength of $10.20 \mathrm{MPa}$, which represents an increase of $34 \%$, relatively to the value obtained by the corresponding paste (BCS). Mortars MHS1 and MCS1 were selected to the next phase of the experimental campaign, based on the compressive strength results. The former was selected even if it showed a slightly lower strength (0.22 MPa) than the mortar MHS2, because it represents a lower aggregate content and also because it allows a direct comparison with the CS-based mortar, also with a $10 \%$ aggregate content (Figure 8).
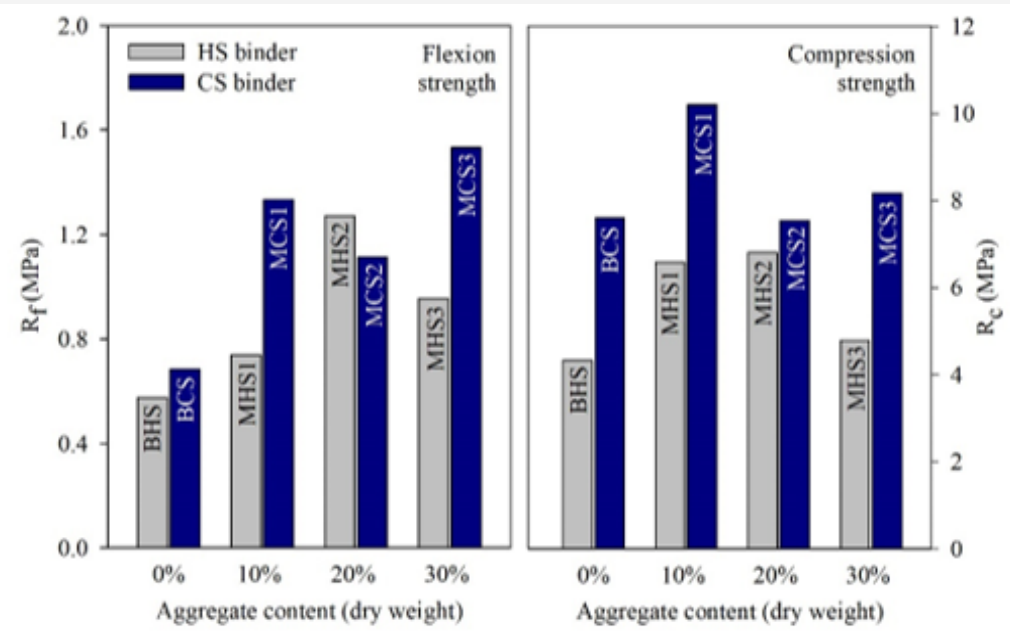

Figure 8: Flexural and compressive strength results on HS-based mixtures and CS-based mixtures, after 20 hours curing at $8^{\circ} \mathrm{C}$.

\section{Bulk density of fresh mixtures}

Figure 9 presents the bulk density of the four mixtures selected for this second phase. The HS-based mixtures showed higher bulk densities than the CS-based mixtures, which can be justified by both the higher specific gravity of the EAFS, relatively to the PS, and the lower activator / solids weight ratios that were used to prepare the HS mixtures. The addition of the aggregate did not represent a significant effect in the bulk density, with increase values of $0.5 \%$ and $3.5 \%$, for the HS and CS mixtures, respectively (Figure 9).

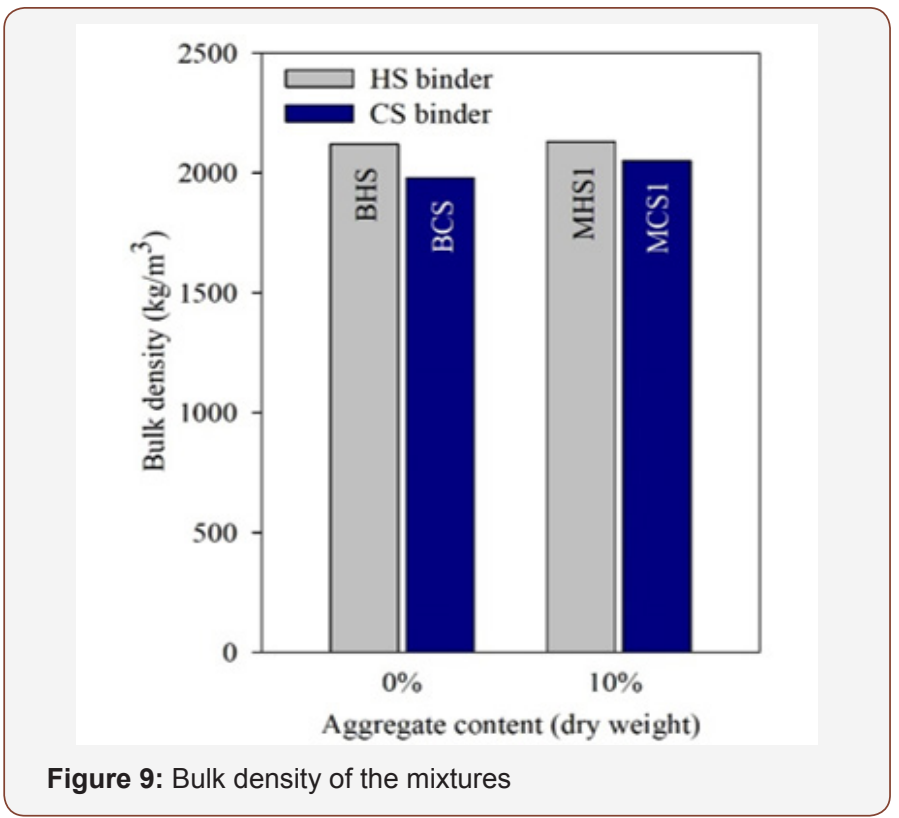

\section{Porosity}

Figure 10 shows the open porosity $\left(\mathrm{p}_{0}\right)$ and the bulk density $\left(\rho_{b}\right)$ of the hardened mixtures, which were determined with the following equations:

$$
\begin{aligned}
& p_{0}=\frac{m_{s}-m_{d}}{m_{s}-m_{h}} \times 100 \\
& \rho_{b}=\frac{m_{d}}{m_{s}-m_{h}} \times \rho_{r h}
\end{aligned}
$$

where $\rho_{\mathrm{rh}}$ is the water density $\left(980 \mathrm{~kg} / \mathrm{m}^{3}\right)$, and $\mathrm{md}$, $\mathrm{ms}$ and $\mathrm{mh}$ represent the dry, saturated and immersed weight.

Mixtures prepared with CS were more porous, which can be related with the higher particle size of the PS, compared with the EAFS particles, and with the higher amount of activator (CS) that was used in the preparation of these mixtures. The addition of sand leads to a decrease in porosity, for mixtures prepared with HS and CS. Therefore, the durability of the mixtures might be improved when sand is added, since the amount of fluids that might propagate through the alkali activated composites will be lower. As expected, the bulk density values of the hardened pastes follow the trends observed for the bulk density of the fresh mixtures, i.e. the HS-based mixtures presented a higher density than the CS-based mixtures. It should also be mentioned that the differences between the bulk density of the hardened mixtures prepared with the same activator are more pronounced than those observed for the bulk density of fresh mixtures (Figure 10). 

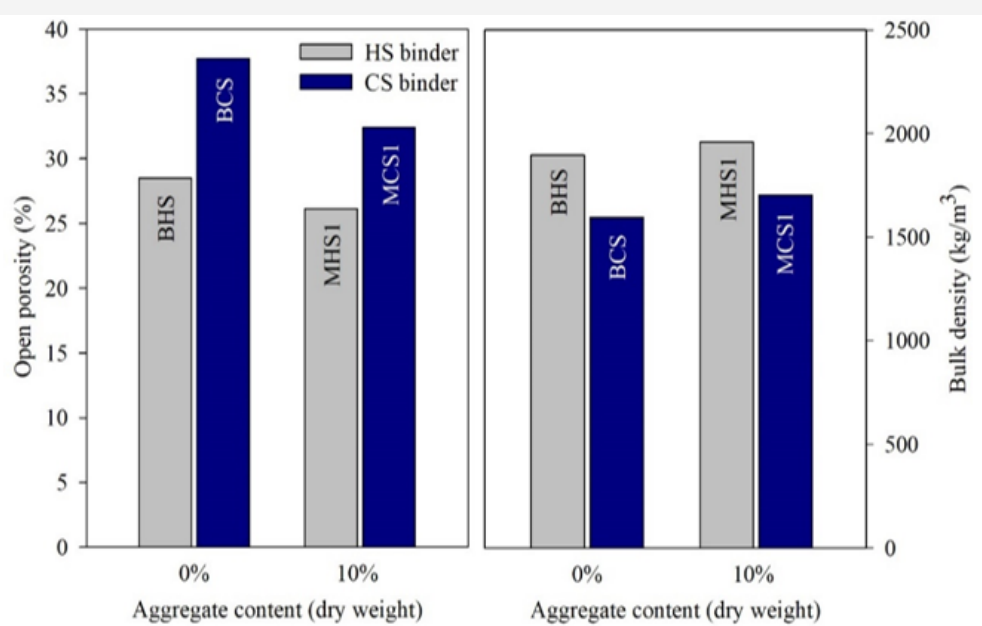

Figure 10: Open porosity (a) and bulk density (b) of the mixtures.

\section{Shrinkage}

Shrinkage values of mixtures MHS1, BCS and MCS1 are shown in Figure 11. Moments before demoulding, some cracks were observed in the BHS specimens, which made them unsuitable for testing. Shrinkage was more significant on mixture MHS1, meaning that the addition of an aggregate only slightly improved the behaviour of the BHS paste. Another important feature regarding the MHS1 mixture is that shrinkage increased with time and, after 56 days, values of more than 10000 microstrains were registered, which is significant, compared with the values of 1750 to 2250 microstrains obtained by Ye et al. [33] and Jia et al. [34], when studying alkali activated ground granulated blast furnace slag mortars. The mixtures containing phosphate sludge showed significant lower shrinkage values after 14 days, of 2600 and 3400 microstrains, for mixtures BCS and MCS1, respectively. These values were then maintained until the 28-day mark, which further reinforces the idea that the use of PS improved the shrinkage behaviour. The CS-based results, after 56 days, should be regarded with some reservation, since, at that stage, both the top and bottom of these specimens displayed significant damages, which influenced the measurements that were carried out on the digital length comparator(Figure 11).

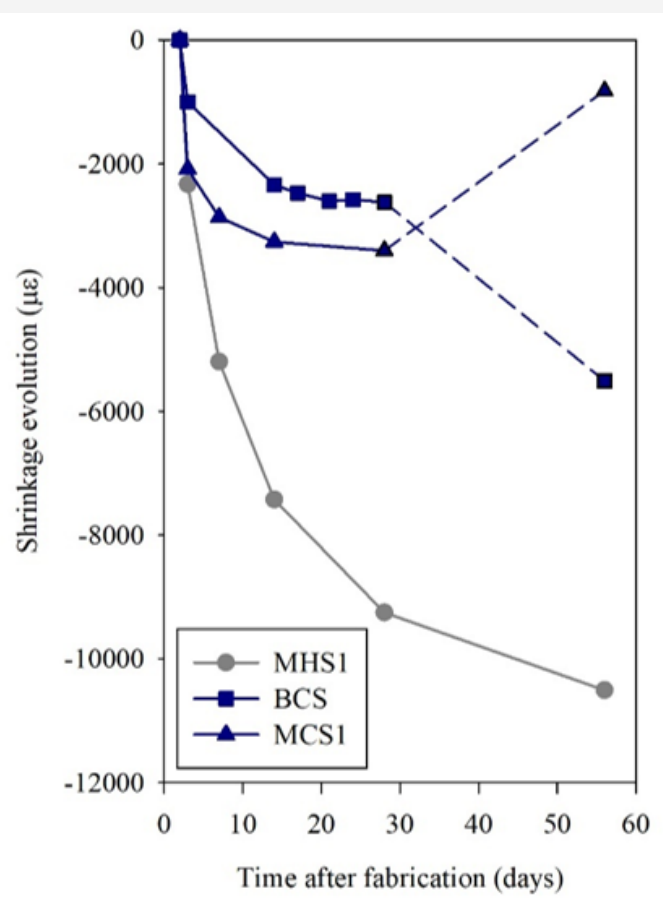

Figure 11: Shrinkage values of mixtures MHS1, BCS and MCS1.

\section{Water absorption}
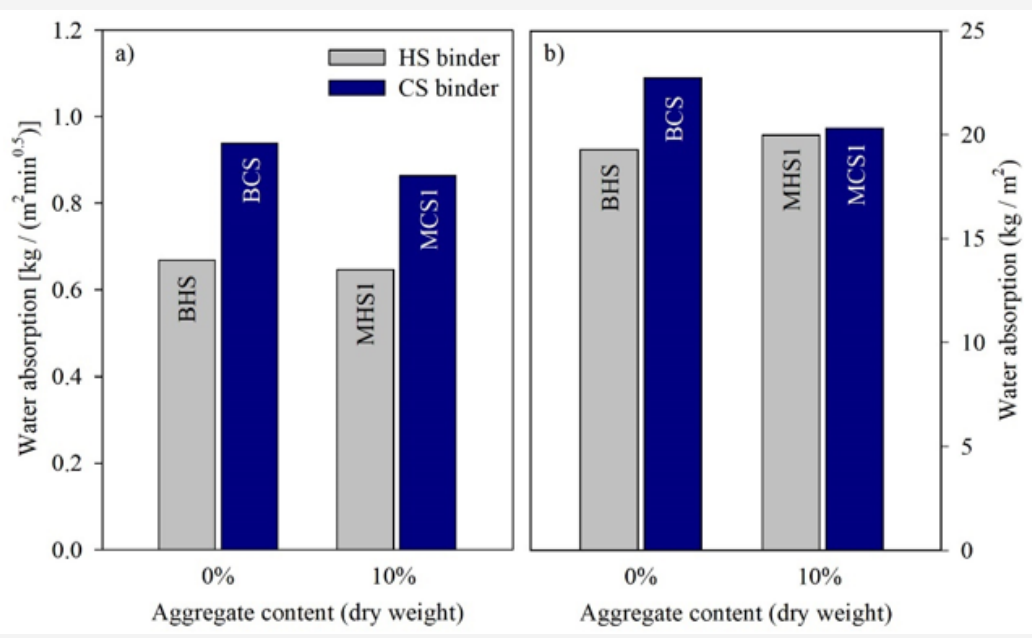

Figure 12: Coefficients of water absorption: (a) for non-renovation mortars; (b) for renovation mortars. 
The coefficients of water absorption are presented in Figure 12. The standard used in this work introduces two methods to determine these coefficients, either for mortars other than renovation mortars $\left(\mathrm{C}_{\mathrm{m}}\right)$ and for renovation mortars $\left(\mathrm{C}_{\mathrm{r}}\right)$, which are given by:

$$
\begin{gathered}
C_{m}=0.1 \times(\mathrm{M} 2-\mathrm{M} 1) \\
C_{r}=0.625 \times(\mathrm{M} 3-\mathrm{M} 0)
\end{gathered}
$$

where M1 and M2 are the masses of the specimens after soaking for 10 and 90 min, respectively, whereas M0 and M3 are, respectively, the dry mass and the mass of the specimens after soaking for 24 hours (Figure 12).

Considering the first case, HS-based mixtures exhibited a lower $\mathrm{Cm}$ than the CS-based mixtures. The inclusion of an aggregate did not produce a significant effect on the water absorption of the mixtures. As water can be a mean of transporting for aggressive agents, it is acceptable to state that mixtures BHS and MHS1 presented a better behaviour regarding this property. Regarding the method for renovation mortars, all mixtures showed a similar behaviour in terms of the coefficient of water absorption. However, after 24 hours, all the water was absorbed, thus not allowing for a proper observation of the height of water penetration in the specimens' surface. It should also be mentioned that at the end of that period, both HS-based specimens released vapors with an acute odor, after being removed from the tray. Additionally, the aluminium tape that was used to seal the specimens was considerably damaged (Figure 13).

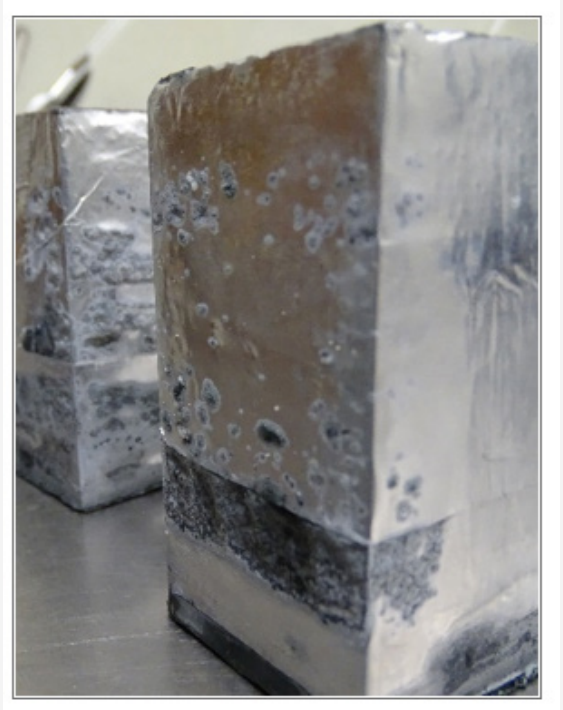

Figure 13: General view of a specimen soaked for 24 hours.

\section{Water-soluble chloride content}

The results of the tests carried out to determine the watersoluble content of the mixtures are depicted in Table 3 and Figure 14. The percentage chloride was computed through the following expression:

$$
\% \mathrm{Cl}=\left(\mathrm{V}_{2}-V_{1}\right) \times f \times \frac{3.545}{10 \times m}
$$

where V1 and V2 are, respectively, the sample and the blank titres of $0.1 \mathrm{M}$ ammonium thiocyanate solution (which are shown in Table 3), and $m$ is the mass of the sample ( $10 \mathrm{~g}$ were weighed for each mixture). The factor of molarity, f, which in the present work was 10.7 , is given by:

$$
f=\frac{m l \text { of } \mathrm{AgNo}_{3}(0.10 \mathrm{~mol} / \mathrm{l})}{\mathrm{ml} \text { of ammoniumthiocyanate }}
$$

Table 3: Water-soluble chloride content test results.

\begin{tabular}{|c|c|c|c|}
\hline Label & $\mathbf{V}_{\mathbf{1}}(\mathbf{m l})$ & $\mathbf{V}_{\mathbf{2}}(\mathbf{m l})$ & \% $\mathbf{C l}$ \\
\hline BN5 & 4.8 & 5.1 & 0.00994 \\
\hline MN5.1 & 4.1 & 5.1 & 0.03313 \\
\hline BCS & 1.75 & 5.1 & 0.11099 \\
\hline MCS.1 & 0.2 & 5.1 & 0.16234 \\
\hline
\end{tabular}

Mixtures BHS and MHS1 showed an appreciable behaviour regarding this particular test: the chloride contents were considerably low and significantly lower than those achieved by the mixtures BCS and MCS1, suggesting that the presence of the phosphate sludge had a significant influence. Nevertheless, the chloride contents exhibited by mixtures BCS and MCS1 are still acceptable. Another important evidence is that the presence of sand leads to higher values of chloride contents (Table 3)(Figure 14).

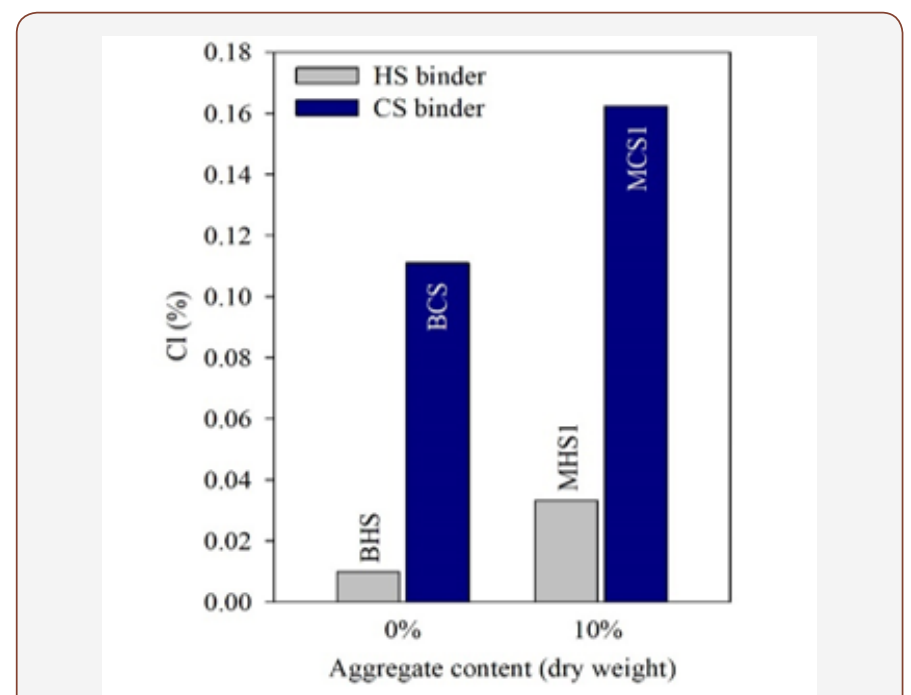

Figure 14: Water-soluble chloride content.

\section{Workability and fluidity tests}

Standard and flow table test consistency: The consistence is an important feature to understand the fluidity of the fresh mixtures. Consistency results, determined with a Vicat apparatus and with the flow table, can be observed in Figure 15. Regarding the standard consistency (Vicat apparatus), no significant differences were found between mixtures BHS and BCS, since, in both cases, the distance between plunger and baseplate was approximately $35 \mathrm{~mm}$, very far from the required distance of $6( \pm 2 \mathrm{~mm})$. It is interesting that considerably different mix designs, both in terms of the EAFS and PS contents and the Ac/Sol weight ratios, still produced similar and comparable results. Regarding the consistency behavior assessed by 
the flow table test mixtures, the CS-based mixtures showed higher flow values than the HS-based mixtures. Even though the hardening process is faster in the pastes prepared with slag and phosphate sludge, these mixtures were prepared with a higher liquid content. Therefore, CS mixtures showed a greatest flow value. Nevertheless, these mixtures attained a higher compressive strength than HSbased mixtures, which is related with the intrinsic properties of the materials and with the type of activator used. Finally, it is also worth noting that flow values decreased when the aggregate was added(Figure 15).
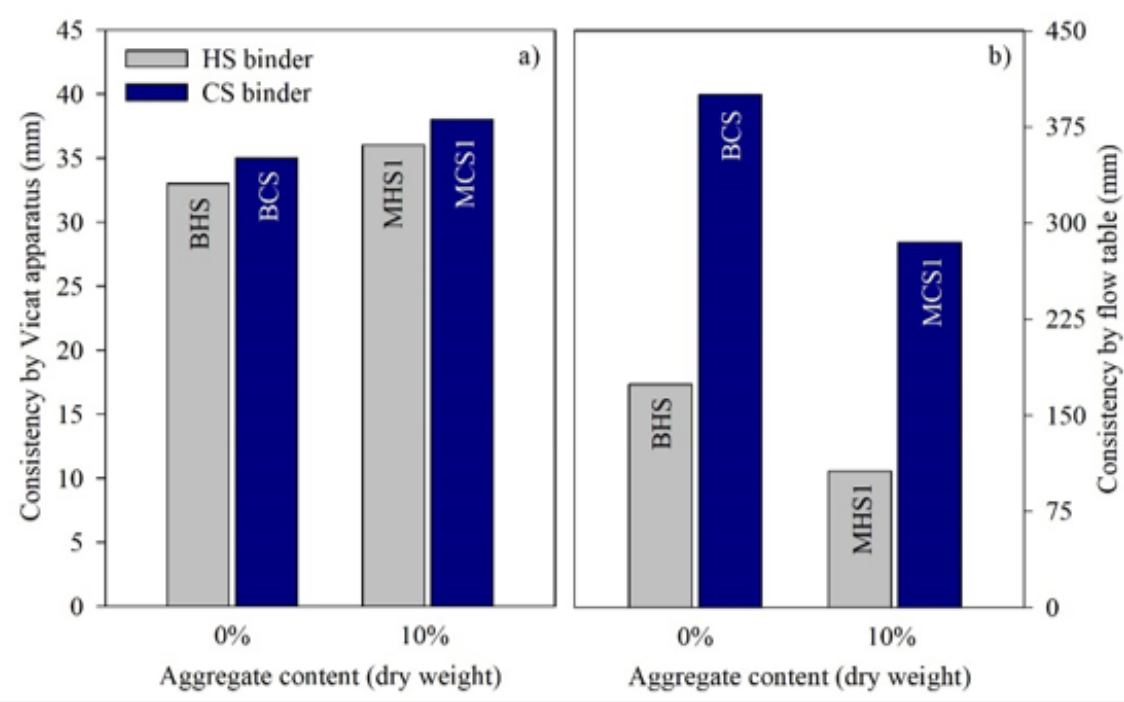

Figure 15: Consistency tests results by the Vicat apparatus (a) and the flow table (b).

Setting times: The initial and final setting times of the studied mixtures are presented in Figure 16. Mixtures that were prepared with slag and phosphate sludge have lower setting times, especially the final setting time, which is of significance since the final setting time is a sign that the mixture has started to harden. Mixtures BCS and MCS1 required less than 50 minutes to achieve such moment. Indeed, during the experimental campaign, casting the mixtures with phosphate sludge was a sensitive task, since the hardening process was significantly faster than with the slag-only mixtures. This strongly affects the workability of the mixtures and, hence, the possible applications for this type of materials might be restricted. On the other hand, the hardening process is slower in mixtures composed only by slag. These results allow to identify the phosphate sludge has a setting time retarding for alkali activated composites (Figure 16).

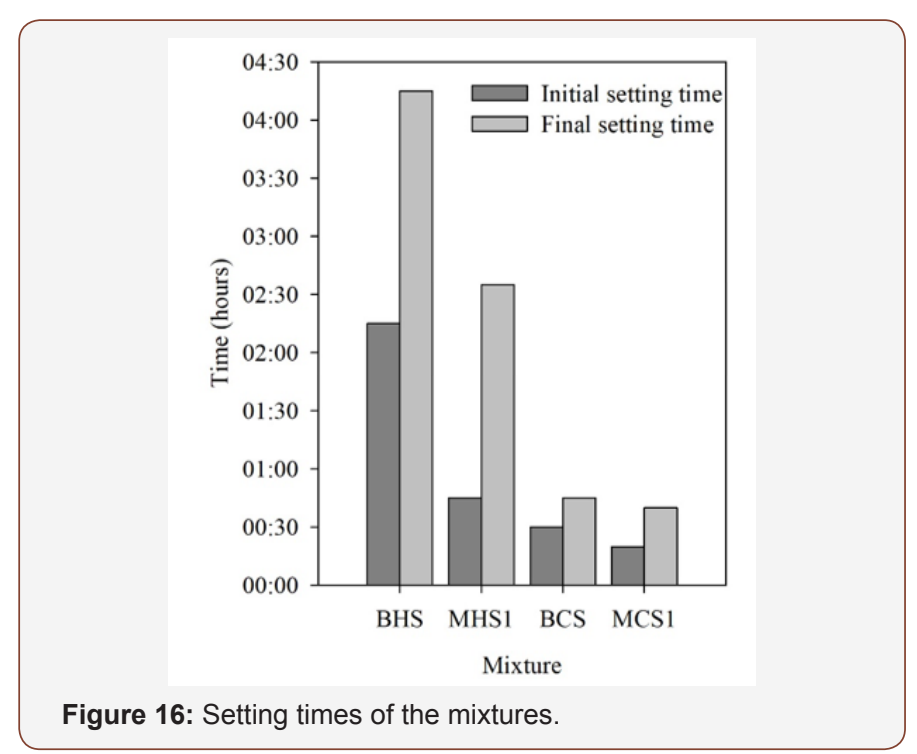

\section{Conclusion}

The present work examines the non-structural performance of alkali activated mixtures incorporating electric arc furnace slag (EAFS) as the main precursor, as well as phosphate sludge (FS) as a potential additive, which were activated using either a commercial solution (HS) or a by-product from the aluminium moulding industry (CS). Different tests were carried out to scrutinize the following properties: bulk density, porosity, shrinkage, water absorption, water-soluble chloride content, workability and fluidity. One of the most relevant findings was that the alkali activated mixture composed exclusively by EAFS exhibited a significant shrinkage after a curing period of 56 days, which is a handicap that should not be disregarded at the moment of defining the possible applications that could be developed with this industrial byproduct. Other relevant aspects are related with the workability: mixtures activated with CS, and having PS in its composition, were significantly more fluid and attained lower setting times than the remaining cases. The results of this experimental campaign suggest that non-structural applications can be designed with this kind of alkali-activated mixtures.

\section{Acknowledgment}

This work was funded by the project GEO-DESIGN - Artifacts for hotels and urban furniture incorporating waste, $\mathrm{n}$ - 17501 , cofinanced by the European Regional Development Fund (ERDF) through NORTE 2020 (North Regional Operational Program 2014/2020). The research was supported by the R\&D Project JUSTREST- Development of Alkali Binders for Geotechnical Applications Made Exclusively from Industrial Waste, with reference PTDC/ECM-GEO/0637/2014, financed by the Foundation for Science and Technology - FCT/MCTES (PIDDAC). 


\section{Conflict of Interest}

No conflict of interest.

\section{References}

1. Arribas I, Santamaría A, Ruiz E, Ortega-López V, Manso JM (2015) Electric arc furnace slag and its use in hydraulic concrete. Constr. Build. Mater 90: 68-79.

2. Santamaría A, Orbe A, Losañez MM, Skaf M, Ortega-Lopez V, et al. (2017) Self-compacting concrete incorporating electric arc-furnace steelmaking slag as aggregate. Mater Design 115: 179-193.

3. Rondi L, Bregoli G, Sorlini S, Cominoli L, Collivignarelli C, et al. (2016) Concrete with EAF steel slag as aggregate: A comprehensive technical and environmental characterisation. Compos. Part B Eng 90: 195-202.

4. Pasetto M, Baldo N (2011) Mix design and performance analysis of asphalt concretes with electric arc furnace slag. Constr. Build. Mater 25 (8): 3458-3468.

5. Coppola L, Buoso A, Coffetti D, Kara P, Lorenzi S (2016) Electric arc furnace granulated slag for sustainable concrete. Constr. Build. Mater 123: $115-119$.

6. Faleschini F, Alejandro Fernández-Ruíz M, Zanini MA, Brunelli K, Pellegrino C, et al. (2015) High performance concrete with electric arc furnace slag as aggregate: Mechanical and durability properties. Constr. Build. Mater 101: 113-121.

7. Pellegrino C, Gaddo V (2009) Mechanical and durability characteristics of concrete containing EAF slag as aggregate. Cem. Concr. Compos 31(9): 663-671.

8. Monosi S, Ruello ML, Sani D (2016) Electric arc furnace slag as natural aggregate replacement in concrete production. Cem. Concr. Compos 66: 66-72.

9. Muhmood L, Vitta S, Venkateswaran D (2009) Cementitious and pozzolanic behavior of electric arc furnace steel slags. Cem. Concr. Res 39 (2): 102-109.

10. Hekal EE, Abo-El-Enein SA, El-Korashy SA, Megahed GM, El-Sayed TM (2013) Hydration characteristics of Portland cement - Electric arc furnace slag blends. HBRC J 9 (2): 118-124.

11. Kim HS, Kim KS, Jung SS, Hwang JI, Choi J-S, et al. (2015) Valorization of electric arc furnace primary steelmaking slags for cement applications. Waste Manage 41: 85-93.

12. Iacobescu RI, Koumpouri D, Pontikes Y, Saban R, Angelopoulos GN (2011) Valorisation of electric arc furnace steel slag as raw material for low energy belite cements. J. Hazard. Mater 196: 287-294.

13. Criado M, Palomo A, Fernández-Jiménez A (2005) Alkali activation of fly ashes. Part 1: Effect of curing conditions on the carbonation of the reaction products. Fuel 84 (16): 2048-2054.

14. Palomo A, Grutzeck M, Blanco M (1999) Alkali-activated fly ashes: A cement for the future. Cem. Concr. Res 29 (8): 1323-1329.

15. Fernández-Jiménez A, Puertas F (1997) Alkali-activated slag cements: Kinetic studies. Cem. Concr. Res 27 (3): 359-368.

16. Puertas F, Fernández-Jiménez A (2003) Mineralogical and microstructural characterisation of alkali-activated fly ash/slag pastes. Cem. Concr. Compos 25 (3): 287-292.

17. Fernández-Jiménez A, Palomo JG, Puertas F (1999) Alkali-activated slag mortars: Mechanical strength behaviour. Cem. Concr. Res 29 (8): 13131321.
18. Provis JL, Palomo A, Shi C (2015) Advances in understanding alkaliactivated materials. Cem. Concr. Res 78: 110-125.

19. Palomo A, Krivenko P, Garcia-Lodeiro I, Kavalerova E, Maltseva O, et al. (2014) A review on alkaline activation: new analytical perspectives. Mater. Constr 64 (315): 24.

20. EN 196-1:2016. Methods of testing cement - Part 1: Determination of strength. CEN - European Committee for Standardization, Brussels, Belgium.

21. Mehdizadeh H, Najafi Kani E, Palomo Sanchez A, Fernández-Jiménez A (2018) Rheology of activated phosphorus slag with lime and alkaline salts. Cem. Concr. Res 113: 121-129.

22. Maghsoodloorad H, Allahverdi A (2015) Alkali-activation kinetics of phosphorus slag cement using compressive strength data. Ceram. Silikaty 59 (3): 250-260.

23. Maghsoodloorad H, Khalili Amiri H, Allahverdi A, Lachemi M, Hossain KMA (2014) Recycling phosphorus slag as a precursor for alkaliactivated binder; Impact of type and dosage of activator. Ceram. Silikaty 58 (3): 227-236.

24. UNE 80103:2013. Métodos de ensayo de cementos. Ensayos físicos. Determinación de la densidad real [Test methods of cements. Physical analysis. Actual density determination]. AENOR - Asociación Española de Normalización y Certificación, Madrid, Spain.

25. EN 1015-6:1998. Methods of test for mortar for masonry - Part 6: Determination of bulk density of fresh mortar. CEN - European Committee for Standardization, Brussels, Belgium.

26. NP EN 1936:2008. Métodos de ensaio para pedra natural. Determinação das massas volúmicas real e aparente e das porosidades total e aberta [Natural stone test methods. Determination of real density and apparent density, and of total and open porosity]. IPQ - Instituto Português da Qualidade, Lisbon, Portugal.

27. BS EN 12617-4:2002. Products and systems for the protection and repair of concrete structures. Test methods. Determination of shrinkage and expansion. BSI - British Standards Institution, London, United Kingdom.

28. EN 1015-18:2002. Methods of test for mortar for masonry - Part 18: Determination of water absorption coefficient due to capillary action of hardened mortar. CEN - European Committee for Standardization, Brussels, Belgium.

29. EN 1015-17:2000. Methods of test for mortar for masonry - Part 17: Determination of water-soluble chloride content of fresh mortars. CEN European Committee for Standardization, Brussels, Belgium.

30. EN 196-3:2016. Methods of testing cement - Part 3: Determination of setting times and soundness. CEN - European Committee for Standardization, Brussels, Belgium.

31. NP EN 445:2008. Caldas de injecção para armaduras de pré-esforço. Métodos de ensaio [Grout for prestressing tendons. Test methods]. IPQ Instituto Português da Qualidade, Lisbon, Portugal.

32. EN 1015-3:1999. Methods of test for mortar for masonry - Part 3: Determination of consistence of fresh mortar (by flow table). CEN European Committee for Standardization, Brussels, Belgium.

33. Ye H, Cartwright C, Rajabipour F, Radlińska A (2017) Understanding the drying shrinkage performance of alkali-activated slag mortars. Cem. Concr. Compos 76: 13-24.

34. Jia Z, Yang Y, Yang L, Zhang Y, Sun Z (2018) Hydration products, internal relative humidity and drying shrinkage of alkali activated slag mortar with expansion agents. Constr. Build. Mater 158: 198-207. 